\title{
The Value of Play in Management Education at University
}

\author{
Emerita Professor Alison James
}

\section{University of Winchester, UK}

\begin{abstract}
This short paper aims to raise awareness of research being undertaken and to invite participation and perspectives via a survey in the first instance. It scopes out the use of playful and play-based teaching and learning at university, identifying its benefits and barriers. It focuses on the value of such approaches in the domains of business and management in higher education and seeks to increase knowledge and critical appreciation of these through a two year project.
\end{abstract}

Keywords: Value of Play, Gamification, Engaging Imagination, Management, Higher Education

Type: Reflective Viewpoint 


\section{The Value of Play}

On a recent flight from Oslo I got chatting to my neighbour who works at a senior level in strategic military communications. He was interested in my exploration of play, observing that 'we play all the time in the military'. When I told him that play for university learning is sometimes dismissed as trivial or childish - the opposite of 'proper' work - he was shocked. At the heart of military training are simulations, exercises and all kinds of activities which count as play, and which in that context are - sometimes literally - deadly serious.

Of course, not all play is denigrated in this way at university. There has been an upsurge of interest and activity with regard to playful learning over the last five years, with The Playful Learning (http://conference.playthinklearn.net/blog/) conference a regular fixture in the UK, and other events such as The Playful University (https://open-tdm.au.dk/blogs/playuni/) hosted in Denmark. However, our conversation in the plane illustrates the divergence of views that exists with regard to play for higher learning. It speaks to the value that we accord play for this purpose, and this is something that I am now exploring further.

To me, denigration of play reflects the extent to which the potential depth and complexity of play in higher education can be underappreciated. I have argued elsewhere that several factors influence our feelings about play in this context. They include our understanding of the term, our views about our roles as educators, expectations and conventions of our field, as well as beliefs as to the nature, identity and purpose of the university. Evidence for this has been accumulating in the last five years.

In 2015 Professor Norman Jackson, Dr Chrissi Nerantzi and I co-edited two issues of Creative Academic, an online magazine, which were dedicated to play in Higher Education. In response to our call, aiming to see if anyone was using play in this context, we received 37 offers of contributions. These all showed us that, irrespective of role or discipline, academics were finding play a valuable pedagogic tool. Four years later, when Chrissi and I published The Power of Play in Higher Education: Creativity in Tertiary Learning (James and Nerantzi, 2019), we had 64 contributions. This interest showed that definitions and applications of play-based and playful learning can be diverse and complex, as well as illustrated how play is being used to teach anything from art to zoology at university. Our work, and that of fellow play proponents (e.g. Whitton and Moseley, 2012) also brings key play theorists (Sutton Smith, 1997, Brown, 2008, Bateson and Martin 2013) into the domain of higher education, rather than focussing on play as part of human and animal behaviour or for child development.

So, how is this relevant to management education and to you as readers of this journal? All disciplines in higher education - and business and management are no exception - are facing the same challenges. How to motivate student engagement, teach diverse cohorts, use multimodal approaches that are inclusive for all, boost employability, develop knowledge, skills and capabilities and add value to the student experience. And so many more; all at a time when resources are stretched and the

International Journal of Management and Applied Research, 2020, Vol. 7, No. 1 
pressure to keep and retain (happy) students is greater than ever. To meet these challenges we need a versatile pedagogic repertoire, including but not limited to, the well-established and accepted.

With regard to play, some forms do appear to be better established and more accepted than others. An obvious example is gamified learning (physical and digital), using games, simulations and competitions. These are often highly structured, with rules and outcomes which are clearly defined from the outset. As we saw in an earlier special issue 'Discovering innovative applications of $L E G O{ }^{\circledR}$ in learning and teaching' that other well established methods, such as LEGO® Serious Play®, are increasingly being used to teach business and management related subjects at university.

Perhaps less familiar than games, simulation and LEGO-based activities are those related to forms of play which step into freer and more experimental territory. One such example from our book is the creation of an artist's residency at Cass Business School to encourage innovation (Holtham and Bech, 2019). Through this the partners sought to 'demonstrate that play and art can be central to enhance understanding and expression in management of organisations' (ibid, p. 173). This resulted in the Spaces 2050 installation; an event involving wearable lighting and the completion of a quest to encourage ideas on how to create a new business school building or "playful urban learning space". Another comes from an article I wrote in 2015 when I was invited by Developing Leaders magazine to write a piece for them on why play has a place in leadership education. It involved spending a day partnered with sheepdogs to develop interpersonal and leadership skills, and to reflect critically on the learning experience. There are variations on this kind of event; however the main objective is for the human to understand how to co-operate with the dog using particular signals and different kinds of behaviour - rather than the verbal/physical cues that they are usually reliant on in normal working environments. Thus it challenges them to rethink how they need to relate to others; particularly relevant for the times when motivators, drives, values and communicating styles are not shared by people in a management relationship or team.

\section{The Project}

At the heart of the factors identified above about how we define and judge play in Higher Education and the challenges enumerated lie issues of how we perceive and value play. This is something I am now exploring with the generous support of the Imagination Lab Foundation (http://www.imagilab.org/), a charitable organisation dedicated to exploring the intersections between the arts, science, business, management, leadership, education, imagination and play. Each of these domains is deeply variegated in nature and all therefore allow for wide participation and interpretation. The aims of this present research are threefold:

$\circ$ To extend knowledge to date of how playful and play-based approaches are being used in university teaching in general;

- To focus specifically on the use of these approaches for business and management programmes in higher education;

International Journal of Management and Applied Research, 2020, Vol. 7, No. 1 
- To explore conceptions of the value of these approaches, using Sutton-Smith's Seven Rhetorics of Play as a cornerstone, in conjunction with principles from play theory more broadly.

In writing this viewpoint I am seeking to raise awareness of this work to make contact with anyone interested in it. This has two objectives - to be able to share its findings more widely and to invite colleagues to expand our shared knowledge base through contributing examples of their own practices. A first step in this is my current survey of the use and value of play in Higher Education, with particular interest in management and business education. If you, the reader, have any interest in the use of play in higher education then I warmly invite you to respond to this survey here: https://value-of-play.onlinesurveys.ac.uk/the-value-of-play-in-higher-education. Your contribution is invaluable as at present there is plenty known about the use of gamified play in business and management education, but far less about other approaches. This is an opportunity to enrich the knowledge base and share it freely for all who are interested in innovative and alternative pedagogies.

The survey is Phase One of the project; Phase Two will be to conduct interviews, workshops and play-based research activities in order to inform the final project outcomes. All survey respondents will have the opportunity to take part in these if they so wish, details of which will become available from May 2020. Phase Three will be the reporting and dissemination of findings, which will be made freely available to all.

If you would like to know more about The Value of Play in Higher Education project, then please visit this resource - Engaging Imagination (https://engagingimagination.com/the-value-of-play/), where you will be able to find a timeline, additional information about the enquiry and participation, and ethical considerations. You can also find about more about me as an academic and independent researcher through my personal bio link.

If you have any questions at all about this research or would like to explore playful learning further please contact me at engagingimaginationdot.com@gmail.com

\section{Resources for further review}

- James, A. (2020), Engaging Imagination, [Online] Available from: https://engagingimagination.com/the-value-of-play/ [Accessed on 20 February 2020].

- James, A. and Nerantzi, C. (Eds.) (2018), "Discovering innovative applications of LEGO ${ }^{\circledR}$ in learning and teaching" [Special Issue], International Journal of Management and Applied Research, Vol. 5, No. 4, https://doi.org/10.18646/2056.54

- The Playful Learning (2020), Playful Learning 2020, UK: University of Leicester [Online] Available from: http://conference.playthinklearn.net/blog/ [Accessed on 20 February 2020].

International Journal of Management and Applied Research, 2020, Vol. 7, No. 1 
- Playful University (2020), Playful attitudes, approaches and activities in learning, teaching and research [Online] Available from: https://opentdm.au.dk/blogs/playuni/ [Accessed on 20 February 2020].

- Imagination Lab Foundation (2012), Imagination Lab Foundation [Online] Available from: http://www.imagilab.org/ [Accessed on 20 February 2020].

- You are warmly invited to respond to the Value of Play survey: https://value-ofplay.onlinesurveys.ac.uk/the-value-of-play-in-higher-education

\section{References}

1. Bateson, P. and Martin, P. (2013), Play, Playfulness, Creativity and Innovation, Cambridge: Cambridge University Press.

2. Brown, S. (2009), Play: How it Shapes the Brain, Opens the Imagination and Invigorates the Soul, New York: Avery.

3. Holtham, C. and Bech, T (2019), "Playful Urban Learning Space- An Indisciplinary Collaboration”, In: James, A. and Nerantzi, C. (Eds), The Power of Play: Creativity in Tertiary Learning, Switzerland: Palgrave, pp. 171-180.

4. James, A. (2015), "Developing Leadership Through Play", Developing Leaders eMagazine, No. 19, p. 23. [Online] Available from: https://www.iedp.com/articles/developing-leaders-magazine-issue-19/ [Accessed on 20 February 2020].

5. James, A. and Nerantzi, C. (2019), The Power of Play: creativity in tertiary learning. Switzerland: Palgrave.

6. Sutton Smith, B. (1997), The Ambiguity of Play. Cambridge Massachusetts: Harvard University Press.

7. Whitton, N. and Moseley, A. (2012), Using games to enhance learning and teaching. UK: Routledge.

International Journal of Management and Applied Research, 2020, Vol. 7, No. 1 